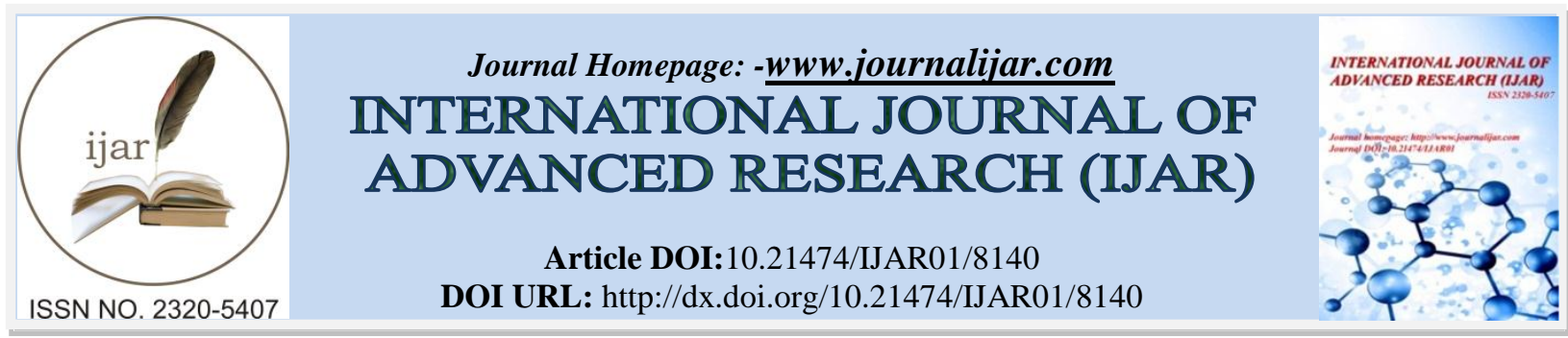

RESEARCH ARTICLE

\title{
CLINICAL PROFILE OF MOTOR NEURON DISEASE IN KASHMIR VALLEY - A HOSPITAL BASED STUDY.
}

Shabir Ahmad Sheikh, Peerzada Mohmad Shafi, Omar Farooq and Syed Insha Saify. Postgraduate Department Of Medicine Government Medical College, Srinagar Kashmir.

\section{Manuscript Info}

\section{Manuscript History}

Received: 01 October 2018

Final Accepted: 03 November 2018

Published: December 2018

Keywords:-

Motor neuron disease, degenerative

disorders, muscular weakness.

\section{Abstract}

Background:-This general term is used to designate a progressive degenerative disorder of motor neurons in the spinal cord, brainstem and motor cortex, manifesting clinically by muscular weakness, atrophy and corticospinal tract signs in varying combinations. There is no report on clinical profile of motor neuron disease or amyotropic lateral sclerosis (ALS) from the state of Jammu and Kashmir.

Objective: To find the clinical profile of motor neuron disease in Kashmir valley.

Methodology:-This hospital based study was conducted on 40 patients of motor neuron disease (MND) visiting OPD / IPD of Department of Medicine, SMHS Hospital. Patients were studied for their presentation, etiology, clinical and laboratory features.

Results:-Majority of our patients i.e. 18 (45\%) were falling in the age group of 51 to 60 years with males more than females with a male to female ratio of 1.85:1. Weakness of muscles was the most common presenting symptom in our patients with fasciculation as the most common motor system findings.

Conclusion:-Motor neuron disorders appear to be a clinically heterogeneous disorder with varied clinical presentation encompassing a range of upper or lower motor neuron dysfunction or both. The patients from Kashmir had disease onset earlier by a decade than most of the studies.

Copy Right, IJAR, 2018,. All rights reserved.

\section{Introduction:-}

This general term is used to designate a progressive degenerative disorder of motor neurons in the spinal cord, brainstem and motor cortex, manifesting clinically by muscular weakness, atrophy and corticospinal tract signs in varying combinations. ${ }^{1}$

Upper motor neuron (UMN) is a motor neuron, the cell body of which lies within the motor cortex of the cerebrum and the axon of which form the corticospinal and corticobulbar tracts.

Lower motor neuron (LMN) - located in the brainstem and spinal cord and send out motor axons that directly innervate skeletal muscle fibres. Spinal cord LMN are also called as anterior horn cells.

Corresponding Author:-Shabir Ahmad Sheikh.

Address:-Postgraduate Department Of Medicine Government Medical College, Srinagar Kashmir. 
Motor neuron disease (MND) encompasses a group of rapidly progressive and universally fatal neurodegenerative disorders of the human motor system. Amyotrophic lateral sclerosis (ALS) is the commonest MND phenotype. ${ }^{2}$

\section{Diagnostic Categories:-}

Clinically definite ALS is defined by clinical or electrophysiological evidence by the presence of LMN as well as UMN signs in the bulbar region and at least two spinal regions or the presence of LMN and UMN signs in three spinal regions.

Clinically probable ALS is defined on clinical or electrophysiological evidence by LMN and UMN signs in at least two regions with some UMN signs necessarily rostral to (above) the LMN signs.

Clinically possible ALS is defined when clinical or electro-physiological signs of UMN and LMN dysfunction are found in only one region, or UMN signs are found alone in two or more regions; or LMN signs are found rostral to UMN signs. Neuroimaging and clinical laboratory studies will have been performed and other diagnosis must have been excluded.

\section{Probable Laboratory Supported ALS}

1. Clinical evidence of upper motor neuron and lower motor neuron signs in only one region, or

2. Upper motor neuron signs alone in one region and lower motor neuron signs defined by EMG criteria in at least 2 muscles of different root and nerve origin in two limbs.

\section{Laboratory Evidence of UMN Involvement:-}

A number of promising imaging and electrophysiological techniques are being used in research studies as potential markers of UMN involvement.

\section{MRI:-}

Sometimes shows abnormal signal intensity in the corticospinal and corticobulbar tracts as they descend from the motor strip via the internal capsule to the cerebral peduncles.

The MR images have showed $\mathrm{T}_{2}$ shortening in precentral cortices. ${ }^{3}$

\section{Diffusion Tensor MRI (DT-MRI):-}

It is a quantitative MRI imaging. It allows measurement of quantities reflecting the size such as Apparent Diffusion Coefficient (ADC) and orientation such as Fractional Anisotropy (FA) of water filled spaces in biological tissues. Compared to controls ALS patients have significantly lower FA in posterior limb of internal capsule, cerebral peduncle, corticospinal and cortico-bulbar tracts. ADC values were inversely correlated with the disease severity. ${ }^{4}$

\section{MRS (proton density - MRS):-}

Combines advantages of MRI with micro-biochemical information. In ALS patients with UMN signs, there is relative reduction of $\mathrm{N}$-Acetylaspartate as compared to creatinine or choline (used as internal standards) in the sensorimotor cortex.

\section{TMS (Transcranial Magnetic Stimulation):-}

An electrophysiological technique used to detect cortical hyperexcitability/impaired inhibition as well as cortical motor neuron and long tract degeneration in ALS. There is increased central motor conduction time, increased absolute latency to a tested muscle. In patients with bulbar onset disease, a absent response to TMS in a limb is supportive of UMN lesion. ${ }^{5}$

\section{Laboratory Evidence of LMN Involvement:-}

World Federation of Neurology has laid down electrodiagnostic criteria for LMN degeneration.

Signs of active denervation ${ }^{6}$

Fibrillations

Positive waves

Signs of chronic partial denervation

Motor unit potential with increased duration

Frequent polyphasia with instability 
High amplitude

Reduced recruitment except in the presence of significant UMN dysfunction.

Aims And Objectives:-

To find the clinical profile of motor neuron disease in Kashmir valley - A hospital based study.

\section{Materials And Methods:-}

The study entitled "Clinical Profile of Motor Neuron Disease in Kashmir Valley" was a hospital based prospective study, conducted in the Postgraduate Department of Medicine, SMHS Hospital, an associated hospital of Government Medical College, Srinagar. Forty (40) patients diagnosed clinically and by using El-Escorial Spain, the World Federation of Neurology established diagnostic criteria for ALS modified at Airline House Virginia in $1998^{7}$ of MND visiting OPD / IPD of Department of Medicine, SMHS Hospital were included for the study.

\section{Exclusion Criteria:-}

1. Predominant cognitive impairment

2. Predominant bowel and bladder involvement

3. Predominant autonomic nervous system dysfunction

4. Predominant sensory impairment

5. Structural lesion on neuroimaging (CT/MRI)

Patients were evaluated and assessed for the following: (i) Gender, (ii) Age of onset, (iii) Pattern of onset, (iv) Presenting symptoms, (v) Cranial nerve involvement, (vi) Motor system involvement, (vii) Any environmental exposure to prior infection, toxins, surgery, trauma and radiation.

Investigations in each case included serum urea, serum creatinine, serum electrolytes, $x$-ray chest, blood sugar, MRI brain and spine and electromyography (EMG). EMG was performed in at least three limbs with Medelec Synergy EMG machine. In addition following tests were done in selected cases like cerebrospinal fluid analysis (CSF), thyroid profile, serum electrophoresis, serum calcium, ANA, CPK, HIV serology, muscle biopsy, nerve conduction studies to rule out other relevant disorders.

The diagnosis of MND was based on clinical findings of a progressive pure motor disorder with muscle weakness, atrophy and fasciculations in the absence of sensory deficit, cognitive impairment and sphincter disturbances. When the above findings were accompanying pyramidal signs, and the modified El-Escorial criteria proposed by World Federation of Neurology was met, a diagnosis of Amyotrophic Lateral Sclerosis was made.

The diagnosis of amyotrophic lateral sclerosis requires:-

The presence of Evidence of lower motor neuron degeneration by clinical, electrophysiological or neuropathological examination. Evidence of upper motor neuron degeneration by clinical examination; and

Progressive spread of symptoms or signs within a region or to other regions, as determined by history, physical examination or electrophysiological tests.

The absence of Electrophysiological or pathological evidence of other disease processes that might explain the signs of LMN and/ or UMN degeneration, and Neuroimaging evidence of other disease processes that might explain the observed clinical and electro-physiological signs.

\section{Statistical Analysis:-}

The data obtained was carefully scrutinized, categorized, coded and statistically analyzed through software package SPSS 16.0 Version. The results were considered significant at $\mathrm{p}$-value $<0.05$.

\section{Results:-}

Majority of the cases i.e. 18 (45\%) were falling in the age group of 51 to 60 years followed by $10(25 \%)$ in the age group of 61 to 70 years. There was male predominance over female with $26(65 \%)$ and $14(35 \%)$ male with a male to female ratio of 1.85:1. Weakness of muscles was the most common presenting symptom with 30 (75\%) of patients followed by wasting of muscles $28(70 \%)$. Fasciculation was commonest motor system findings with 36 
(90\%) followed by decreased power $34(80 \%)$. XII cranial nerve was the most common nerve affected [24 (60\%) of patients]. Cranial nerves (I-VIII) were intact in all cases. Limb onset pattern was more common than bulbar onset $26(65 \%)$ and $14(35 \%)$ respectively. Out of $26(65 \%)$ patients with limb onset pattern upper limb onset was seen in $16(61.44 \%)$ of patients. $28(70 \%)$ patients were smokers, $4(10 \%)$ had prior history of trauma, none of our patient had any exposure to toxins or radiation.

There were $18(45 \%)$ farmers in our study, followed by $16(40 \%)$ labourers with $12(30 \%)$ housewives. 12 (30\%) patients had hyperintense signals in corticospinal tract areas on MRI with $24(60 \%)$ normal findings.

Table 1:- Age and Gender Wise Distribution of the Studied Subjects

\begin{tabular}{|c|c|c|c|c|}
\hline \multirow{2}{*}{ Age Group (Years) } & \multicolumn{2}{|c|}{ Male } & \multicolumn{2}{c|}{ Female } \\
\cline { 2 - 5 } & No. & No. & 0 \\
\hline 30 & 0 & 0 & 1 & 0 \\
\hline $31-40$ & 3 & 7.5 & 2 & 5 \\
\hline $41-50$ & 4 & 10 & 6 & 15 \\
\hline $51-60$ & 12 & 30 & 6 & 15 \\
\hline $61-70$ & 4 & 10 & 1 & \\
\hline$>70$ & 1 & 2.5 & & 2.5 \\
\hline
\end{tabular}

Table :-2

\begin{tabular}{|l|l|c|c|}
\hline \multicolumn{2}{|c|}{ Symptoms } & No. of Patients & Percentage \\
\hline \multirow{5}{*}{} & Weakness of muscles & 30 & 75 \\
\cline { 2 - 4 } & Wasting of muscles & 28 & 70 \\
\cline { 2 - 4 } & Twitching & 26 & 65 \\
\cline { 2 - 4 } & Difficulty in speech & 14 & 35 \\
\cline { 2 - 4 } & Stiffness of limbs & 18 & 45 \\
\cline { 2 - 4 } & Dysphagia & 4 & 10 \\
\cline { 2 - 4 } & Emotional Lability & 8 & 20 \\
\hline \multirow{5}{*}{ Motor System } & Fasciculation's & 36 & 90 \\
\cline { 2 - 4 } & Decreased power & 34 & 85 \\
\cline { 2 - 4 } & Decreased Bulk & 32 & 80 \\
\cline { 2 - 4 } & Decreased tone & 32 & 80 \\
\cline { 2 - 4 } & Spasticity & 24 & 60 \\
\hline \multirow{5}{*}{ Cranial Nerve Involvement } & IX & 8 & $20 \%$ \\
\cline { 2 - 4 } & X & 8 & $20 \%$ \\
\cline { 2 - 4 } & XI & 6 & 15 \\
\cline { 2 - 4 } & XII & 24 & 60 \\
\hline
\end{tabular}

Table :-3

\begin{tabular}{|l|l|c|c|}
\hline \multicolumn{2}{|c|}{} & \multicolumn{1}{c|}{ No. of Patients } & Percentage \\
\hline Pattern of Onset & Limb & 26 & 65 \\
\cline { 2 - 4 } & Bulbar & 14 & 35 \\
\hline \multirow{4}{*}{$\begin{array}{l}\text { Pattern of Onset Among Onset } \\
\text { Limb }\end{array}$} & 16 & 61.44 \\
\cline { 2 - 4 } & Lewer limb onset & 7 & 3.8 \\
\cline { 2 - 4 } & Monomelic & 1 & 3.8 \\
\cline { 2 - 4 } & Paraparetic & 1 & 3.8 \\
\cline { 2 - 4 } & Flail arm & 1 & 60 \\
\hline \multirow{5}{*}{ MRI Brain Findings } & Normal Study & 24 & 30 \\
\cline { 2 - 4 } & $\begin{array}{l}\text { Hyperintensities in corticospinal } \\
\text { tract area }\end{array}$ & 12 & 10 \\
\cline { 2 - 4 } & Cerebral atrophy & 4 & \\
\hline
\end{tabular}


Table 4:-Result of the Investigations done as a workup for secondary causes of MND

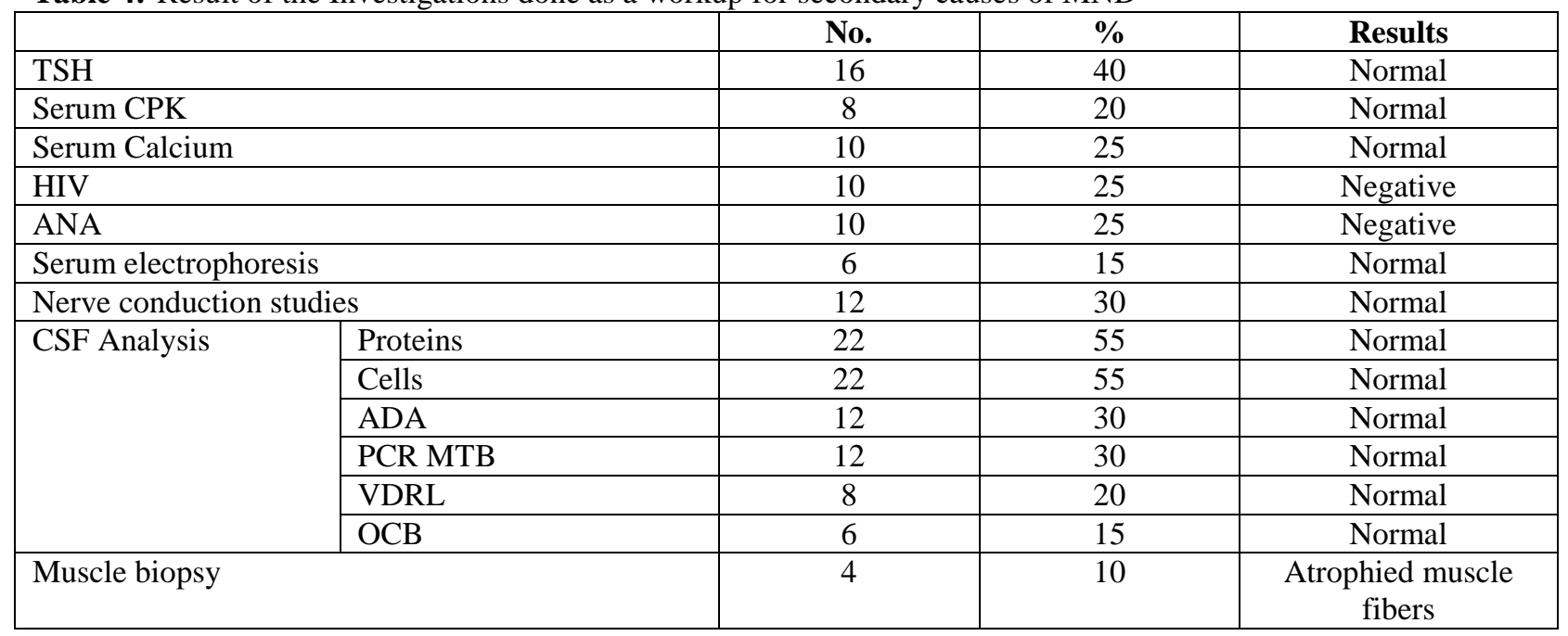

\section{Discussion:-}

The study entitled "Clinical Profile of Motor Neuron Disease in Kashmir Valley" was a hospital based prospective study conducted in the Postgraduate Department of Medicine, SMHS Hospital, an associated hospital of Government Medical College, Srinagar during 2009 to 2011. 40 patients of MND visiting OPD / IPD of Department of Medicine, SMHS Hospital were included for the study

Out of 40 patients, $26(65 \%)$ were males and $14(35 \%)$ were females. Male to female ratio was $1.85: 1$, suggesting a male predominance. Similar gender distribution has been reported by Bracco L et al ${ }^{8}$ who found male to female ratio of 1.3:1, Lopez Vega JM et $\mathrm{al}^{9}$ reported male to female ratio of 1.78:1, Yoshida $\mathrm{S}$ et $\mathrm{al}^{10}$ found male to female ratio of 1.85:06, Argyriou AA et al ${ }^{11}$ reported male to female ratio of 1.44:1. Male predominance has also been reported by Govoni $\mathrm{V}$ et $\mathrm{al}^{12}$ Swenson LW et $\mathrm{al}^{13}$ and Saha et $\mathrm{al}^{14}$.

Majority of the patients in our study were falling in the age group of 51-60 years (18 out of 40, 45\%) followed by $61-70$ years age group (10 out of $40,25 \%)$.

The peak age group involved in motor neuron disease has been $6^{\text {th }}$ to $7^{\text {th }}$ decade as reported by Yoshida $\mathrm{S}$ et a ${ }^{10}$ at 60-69 years, Annegers $\mathrm{JF}^{15}$ reported peak age group at 65-70 years, Hojer-Pederson E et $\mathrm{al}^{16}$ reported peak age group at $64 \pm 10$ years, Fong $G$ et al $^{17}$ reported peak age group at $60-69$ years. There have been a few studies reporting even a later peak age group like Mandrioli $\mathrm{J}$ et $\mathrm{al}^{18}$ who reported 75-79 years as peak age group, Piemonte et $\mathrm{al}^{19}$ reported 70-79 years age as peak age group. The peak age group in our study was a decade earlier compared to most of the literature cited, though Saha SP et $\mathrm{al}^{14}$ from India has reported 41-50 years as the peak age group in his study.

Higher peak age of onset was noticed in the female compared to male. The most common presenting symptom of the patients in our study was found to be weakness of the muscles (30 patients out of 40,75\%) followed by wasting of muscles (28 patients out of 40,70\%). Saha SP et al ${ }^{14}$ from India has also reported weakness and wasting of muscles as the most common presenting symptom in $80 \%$ cases.

The most common motor system finding on examination was fasciculations seen in 36 patients (90\%) followed by decreased power seen in 34 patients (85\%), decreased bulk and decreased tone was found in 32 patients each (80\% each). Chopra et $\mathrm{al}^{20}$ reported fasciculations in $80 \%$ cases while Saha SP et al ${ }^{14}$ found fasciculations in $52 \%$ of cases.

The most common pattern of onset of disease was limb onset 26 patients (65) followed by bulbar onset 14 patients (35\%). Among the limb onset ( $\mathrm{n}=26)$, upper limb onset was found in 16 patients out of $26(61.4 \%)$, lower limb onset was found in 7 patients out of $26(26.9 \%)$. One patient each had monomelic, paraparetic and flail arm presentation. The European Subgroup Study ${ }^{21}$ (Italy, Spain, Germany) has found limb onset in $82 \%$ patients and bulbar onset in 
$18 \%$ of patients. Onset of muscle weakness has been reported ${ }^{22}$ more common in the upper than the lower extremities but in $25 \%$ of patients weakness begins in bulbar innervated muscles.

Regarding cranial nerves the most common involved cranial nerve was $12^{\text {th }}$ nerve seen in 24 patients $(60 \%)$ followed by $9^{\text {th }}, 10^{\text {th }}$ and $11^{\text {th }}$ nerves respectively involved in $8(20 \%), 8(20 \%)$ and $6(15 \%)$ cases. In none of the patients were other nerves involved though Saha SP et al ${ }^{14}$ has reported cranial nerve $12^{\text {th }}$ as the most common nerve involved in $50 \%$ cases followed by $9^{\text {th }}$ and $10^{\text {th }}$ in $40 \%$ cases each and $11^{\text {th }}$ in $16 \%$ cases.

There have been many studies relating motor neuron disease with the environmental factors like rural residence, socioeconomic status, occupation, exposure to heavy metals or toxins, prior surgical intervention, prior trauma.

Bharucha $\mathrm{NE}$ et $\mathrm{al}^{23}$ related rural farming and lower socio-economic status with the occurrence of motor neuron disease. Granieri $\mathrm{E}$ et $\mathrm{al}^{24}$ found higher incidence of motor neuron disease in farmers and patients of rural areas and patients with prior history of trauma. GawelM et $\mathrm{al}^{25}$ has found increased incidence of motor neuron disease in patients with antecedent back injury and electric shock. Holloway SM et $\mathrm{al}^{26}$ found relation between motor neuron disease and electric workers and rubber workers. Mandrioli $\mathrm{J}$ et $\mathrm{al}^{18}$ found higher incidence in mountainous areas where agriculture was more common. But there have also been studies which have found no relation between motor neuron disease and environmental exposure. GawelM et $\mathrm{al}^{25}$ found no increased incidence of head injuries, fractures or malignancy in cases of motor neuron disease compared to controls. Bharucha NE et al ${ }^{23}$ found no relation of motor neuron disease with urbanization, lead or mercury exposure. $\mathrm{TM} \mathrm{Li}$ et al ${ }^{27}$ found no relation with occupational exposure to leather products, trauma or surgical procedures to the motor neuron diseases. Govoni $\mathrm{V}$ et al ${ }^{12}$ found no relation as such with the rural residence.

In our study, most of the patients were labourers and farmers and belonging to the rural areas. Few patients were also exposed to prior surgery, trauma but it needs a study on a larger scale before any definite conclusion can be drawn.

Role of neuroimaging in motor neuron disease is primarily to rule out the secondary causes of motor neuron disease. Per se there are no specific findings reported for motor neuron disease, though cortical hyperintensities have been reported by many investigators. In our study majority of the cranial MRIs were normal, however, 12 patients (30\%) had corticospinal region hyperintensities.

\section{Conclusion:-}

A total of 40 patients of motor neuron disease were studied, out of which $26(65 \%)$ were males and 14 (35\%) were females. Male to female ratio was 1.85:1. The most common involved age group was 51-60 years (45\%) which is a decade earlier than most of the studies. Peak age of onset in females was found to be a decade later than males.Bulbar onset was found in $35 \%$ of cases which is higher compared to most of the studies.Most common cranial nerve affected was 12 th. Most of the patients were labourers or farmers by profession.No definite relation was found between environmental exposures with the disease.

Motor neuron disorders appear to be a clinically heterogeneous disorder with varied clinical presentation encompassing a range of upper or lower motor neuron dysfunction or both.

\section{Bibliography:-}

1. Allan H. Ropper, Robert H. Brown, Adams and Victors: Principles of Neurology. $8^{\text {th }}$ edition, Page 838. McGraw Hill Publishers.

2. Kiernan MC, Vucic S, Cheah BC, Turner MR, Eisen A, Hardiman O, et al. Amyotrophic lateral sclerosis. The Lancet. 2011; 377(9769): 942-55

3. H Oba, T Araki, S Monzana, K Ohtomo. ALS: $\mathrm{T}_{2}$ shortening in motor cortex at MR imaging. Radiology Dec. 1993; 189: 843-846.

4. Oreja-Guevara C, Rodriguez de Rivera FJ, Alonso Clarke R, Alvarez Linera J, Diez-Tejedor E. Diffusion anisotropy imaging in ALS. ALS 2007; 8: 134.

5. Mamede de Carvalho et al. Electrodiagnostic criteria for diagnosis of ALS. Clinical Neurophysiology 2008; 119: 497-503. 
6. Acary Souza BulleOliveria, Roberto Diast Batista Pereira. Amyotrophic lateral sclerosis (ALS). Three letters that change the people's life. ArqNeuropsiquiatr 2009; 67(3-A): 750-782.

7. Brooks B, Miler R, Swash M et al. World Federation of Neurology Research Group on Motor Neuron Disease 2000, El-Escorial Revisited: Revised criteria for the diagnosis of amyotrophic lateral sclerosis. AmLatScl. Vol. 1: pp 293-299.

8. Bracco L, Antisono P, Amaducei L. Study of epidemiological and etiological factors of ALS in the province of Florences Italy. ActaNeurolScand 1979 Aug; 60(2): 112-24.

9. Lopez-Vega JM, Calleja J et al. Motor neuron disease in Cantabria, North Spain. ActaNeurolScand 1988 Jan; 77(1): 1-5.

10. Yoshida S, Uebayashi Y, Kihira T, Kohmoto J, Wakayama I,Taguchi S, Yase Y. Epidemiology of MND in the Kii Peninsula of Japan. J NeurolSci 1998 Mar 5; 155(2): 146-55.

11. Argyriou AA, Polychromopoulos P, Papapetropoulos S, Ellul J, Andriopoulos I, Katsoulas G, Salakou S, Chroni E. Clinical and epidemiological features of MND in south-western Greece. ActaNeurolScand 2005; 111: 108-113.

12. Govoni V, Granieri E, Fallica E, Casetta I. ALS, rural environment and agricultural work in the local health district of Ferrara ,Italy in the year 1964-1998. J Neurol 2005 Nov; 252(11): 1322-7.

13. Swenson LW, Cwik VA, Martin WR. The prevalence of MND in the province of Alberta. Can J NeurolSci 1999 May; 26(2): 119-22.

14. Saha SP, Das SK, Gandopadhyay PK, Roy TN, Maiti B. Pattern of MND in Eastern India. Acta Neuron Scand 1997; 96: 14-21.

15. Annegers JF, Appel S, Lee JR, Perkins P. Incidence and prevalence of ALS in Aarris Country, Texas. Arch Neurol 1991 Jun; 48(6): $\quad$ 589-93.

16. Hojer-Pedersen E, Christensen PB, Jensen NB. Incidence and prevalence of MND in two Danish countries. Neuroepidemiology 1989; 8(3): 151-9.

17. Fong GC, Chen TS, Lam K, Cheng WK, Mok KY, Chim CS, Ho SL. An epidemiological study of MND in Hong Kong. Amyotroph Lateral Scler Other Motor NeurolDisord 2005 Sept; 6(3): 164-8.

18. Mandrioli J, Faglioni P, Merelli E, Sola P. The epidemiology of ALS in Modena, Italy. Neurology 2003 Feb; 60(4): 683-9.

19. Piemonte and Valle d'. Registrar for ALS (PARALS). Incidence of ALS in Italy: evidence for a uniform frequency in western countries. Neurology 2001 Jan 23; 56(2): 239-44.

20. Chopra JS, Prabhakar S, Singh AP, Banerjee AK. Pattern of motor neuron disease in north India and wasted leg syndrome. In: Gouri Devi M. ed. Motor Neuron Diseases, New Delhi. Oxford and IBH Publishing, 1984: 16570.

21. Dengler R. Current treatment pathways in ALS: a European perspective. Neurology 1999; 53(Suppl): S4-S10.

22. Walter G, Bradley, Robert B Daroff, Gerald M. Fenichal, Joseph Jankovic. Neurology in Clinical Practice. $4^{\text {th }}$ Edition, Vol. 2, Page 2203.

23. Bharucha NE, Schoenberg BS, Raven RH, Pickle LW, Byar DP, Mason TJ. Geographical distribution of MND and correlation with possible etiological factors. Neurology $1983 \mathrm{Jul}$; 33(7): 911-5.

24. Granieri E, Carreras M, Tola R, Paoline E, Trali G, Eleopra R,Serra G. et al. Motor neuron disease in the province of Ferrara, Italy. Neurology 1988 Oct; 38(10): 1604-8.

25. Gawel M, Zaiwalla Z, Rose FC. Antecedent events in MND. J NeurolNeurosurg Psychiatry 1983 Nov; 46(11): 104-3.

26. Holloway SM, Mitchell JD. MND in the Lothian region of Scotland (1961-1981). J Epidemiol Community Health 1986 Dec; 40(4): 344-50.

27. TM Li, E Alberman and M Swash. Clinical features and association of 560 cases of MND. J NeurolNeurosurg Psychiatry 1990 Dec; 53(12): 1043-1045. 